\section{Tumor-derived blood vessels-a new therapy target?}

Tumor cells may be able to mimic vascular cells and form their own blood vessels, according to a new study. The findings could go some way towards explaining how blood flow is maintained in some glioblastomas even after inhibition of angiogenesis by therapies that target vascular endothelial growth factor (VEGF), and the tumor cell-lined vessels could represent a new therapeutic target for glioblastoma.

Using immunohistochemical analysis, Soufiane El Hallani and colleagues identified a subset of glioblastomas containing tubular structures that expressed vascular basement membrane markers (PAS and collagen IV) but lacked expression of the endothelial marker CD34. The cells lining the vessels exhibited amplification of the epidermal growth factor receptor gene and were, therefore, positively identified as tumor cells. The formation of tubular vascular channels by tumor cells, termed tubular vasculogenic mimicry, cannot be halted by traditional antivascular therapies. As El Hallani explains, "it would be prudent to target tumor cell-lined vessels because they may participate in the antiangiogenic resistance by providing an alternative pathway for glioblastoma vascularization."

The term 'vasculogenic mimicry' has been used previously to describe the formation of patterned matrix-associated channels, which do not mimic blood vessels morphologically. By contrast, El Hallani points out that the tubular-type vessels found in glioblastoma "may be confused morphologically with endothelial celllined blood vessels." He adds "we have to determine the sensitivity of such unexpected vessels to current antiangiogenic therapies and identify their role in intrinsic or acquired anti-VEGF resistance."

\section{Carolyn McSharry}

Original article El Hallani, S. et al. A new alternative mechanism in glioblastima glioblastoma vascularisation: tubular vasculogenic mimicry. Brain 133, 973-982 (2010)
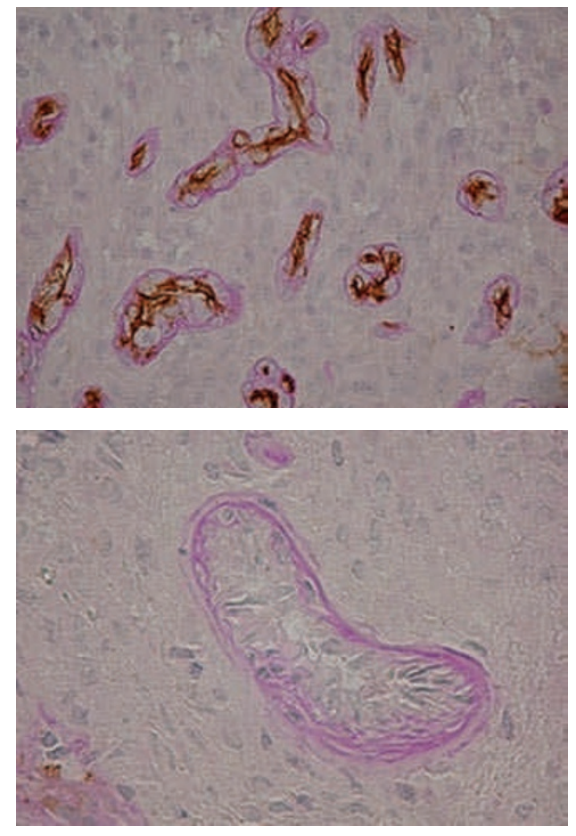

Top: tumor angiogenic vessels expressing the endothelial marker CD34 (brown) and the vascular basement membrane marker PAS (magenta). Bottom: tubular vessels lacking CD34 expression. Image provided by Dr Soufiane El Hallani. 